J. Lake Sci.(湖泊科学), 2016, 28(2): 253-262

DOI 10. 18307/2016. 0203

(c) 2016 by Journal of Lake Sciences

\title{
秋季聚积蓝藻打捞对蓝藻生长及水质影响的原位实验
}

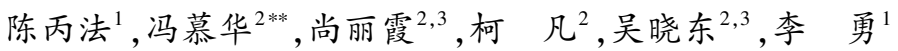 \\ (1: 苏州科技学院环境科学与工程学院,苏州 215009) \\ (2: 中国科学院南京地理与湖泊研究所湖泊与环境国家重点实验室,南京 210008) \\ (3: 中国科学院大学, 北京 100049)
}

\begin{abstract}
摘 要: 在巢湖西北半湖近岸设置 3 组小型围隔模拟秋季湖岸带蓝藻聚积, 并用单片鳃式过滤器原位打捞蓝藻, 研究秋 季打捞对蓝藻生长的影响及其对营养盐、藻源性有机物的控制效应. 初始围隔水体叶绿素 a 浓度为 $309.5 \pm 3.7 \mu \mathrm{g} / \mathrm{L}$, 总 氮和总磷浓度分别为 $3.32 \pm 0.14$ 和 $0.30 \pm 0.04 \mathrm{mg} / \mathrm{L}$. 蓝藻衰亡分解释放的藻源性有机物为水体溶解性有机物的主要来 源, 苂光有机物以类蛋白物质为主. 经过打捞, 浮游植物生物量削减了 $41.7 \%$, 解除了蓝藻生长 “密度制约”, $24 \mathrm{~h}$ 细胞分 裂频率及原位生长速率均增大, 说明打捞在短期内增强蓝藻细胞生长活力, 减缓藻源性有机物的释放. 与秋季蓝藻衰亡 趋势一致, 实验周期内围隔中叶绿素 $\mathrm{a}$ 浓度逐渐降低, 秋季打捞不会造成蓝藻水华再次暴发. 打捞通过削减蓝藻生物量, 使水体初级生产力、氮、磷、高镇酸盐指数得到显著控制; 而且打捞还可以控制藻源性有机物的释放, 使藻源性大分子有 机物更易降解为小分子有机物. 因此, 在秋季对湖岸带聚积蓝藻进行物理打捞, 不仅可以控制蓝藻生物量, 还可以有效控 制营养盐和有机物的释放,降低生态风险.
\end{abstract}

关键词: 巢湖;蓝藻聚积; 打捞; 营养盐; 藻源有机物

\section{Effects on cyanobacterial growth and water quality after harvesting accumulated cya- nobacteria in autumn: an in-situ experiment in Lake Chaohu}

\author{
CHEN Bingfa ${ }^{1}$, FENG Muhua $^{2 * *}$, SHANG Lixia ${ }^{2,3}$, KE Fan $^{2}$, WU Xiaodong ${ }^{2,3}$ \& LI Yong ${ }^{1}$ \\ (1: School of Environmental Science and Engineering, Suzhou University of Science and Technology, Suzhou 215009, P.R. \\ China) \\ (2: State Key Laboratory of Lake Science and Environment, Nanjing Institute of Geography and Limnology, Chinese Academy \\ of Sciences, Nanjing 210008, P.R. China) \\ (3: University of Chinese Academy of Sciences, Beijing 100049, P.R.China)
}

Abstract:An in-situ enclosure experiment was conducted to study the effect of harvesting of algae on cyanobacteria growth and water quality in the northwestern Lake Chaohu in autumn. The gill type filter was used to harvest cyanobacteria in two enclosures and no treatment was conducted in control enclosure. The growth rates of cyanobacteria and the concentrations of nutrients and organic matters were investigated after harvesting compared with that in the control. The initial concentrations of chlorophyll-a, total nitrogen and total phosphorus reached 309. $5 \pm 3.7 \mu \mathrm{g} / \mathrm{L}, 3.32 \pm 0.14 \mathrm{mg} / \mathrm{L}$ and $0.30 \pm 0.04 \mathrm{mg} / \mathrm{L}$, respectively. Algogenic organic matter became a major source of dissolved organic matter in the enclosures, and fluorescent dissolved organic matter was dominated by proteinoid materials. Harvesting reduced the cyanobacterial biomass by $41.7 \%$, which relieved the " density dependence of growth" of cyanobacteria, and then resulted in an increase in diel frequency of dividing cells and the in-situ growth rates of cyaobacteria. Algogenic organic matters were reduced due to harvesting increased the viability of cyanobacterial cells in a short term. What's more, cyanobacteria tended to decline in autumn and chlorophyll-a concentration dropped gradually in the enclosures, which testified that harvesting in autumn would not cause a second outbreak of algal bloom. Primary productivity, nitrogen and

* 国家水体污染控制与治理科技重大专项(2012ZX07103-005)、中国科学院南京地理与湖泊研究所学科交叉与前沿 项目 (NIGLAS2012135013) 和江苏高校水处理技术与材料协同创新中心项目联合资助. $2015-05-15$ 收稿; 201508-26 收修改稿. 陈丙法 (1990 ), 男, 硕士研究生; E-mail :cbingfa@ 126.com.

** 通信作者;E-mail: mhfeng@ niglas.ac.cn. 
phosphorus nutrients, Potassium permanganate index were controlled significantly in the harvesting enclosures due to the reduction of cyanobacterial biomass. Furthermore, the release of algogenic organic matters was controlled and macromolecular organic compound was degraded easily to low-molecular-weight organics. Therefore, harvesting the accumulated cyanobacteria shoreside in autumn could control the amount of algae, nitrogen and phosphorus nutrients as well as the release of algogenic organic matters, which could reduce the ecological risk in lakes.

Keywords: Lake Chaohu; accumulative cyanobacteria; harvest; nutrients; algogenic organic matter

随着湖泊流域及其周边地区人口增长和经济快速发展, 我国多数湖泊水环境质量不容乐观, 水体富营 养化严重,蓝藻水华频繁暴发 ${ }^{[1]}$. 在蓝藻水华暴发季节,静风条件下蓝藻会向水体表层垂直上浮,形成可移 动的水华表层 ${ }^{[2]}$. 水体表层的蓝藻易受盛行风的驱动, 水平迁移至下风向区域形成大量藻体聚积, 造成严重 的水华灾害 ${ }^{[2]}$. 蓝藻聚积时, 水体溶解氧大量消耗, 蓝藻死亡散发恶臭并释放有毒有害物质, 水质恶化严 重 ${ }^{[3-4]}$, 严重威胁当地取水安全. 另外, 部分聚积蓝藻在秋季会下沉至湖底休眠越冬, 作为 “种子库”, 增大来 年蓝藻水华暴发的可能性 ${ }^{[5]}$. 因此, 有效控制湖岸带蓝藻聚积不但可以改善水质, 带来良好的社会、经济效 益, 还潜藏着巨大的生态效益.

蓝藻水华的控制方法主要包括物理方法、化学方法和生物方法 ${ }^{[6]}$. 在夏、秋季蓝藻暴发期间, 需要对聚 积蓝藻进行应急控制. 化学方法对水质有负面影响, 生物方法以长期防治为主, 蓝藻打捞技术作为一种简单 易行、见效快、副作用小的物理技术, 已普遍应用于蓝藻原位应急控制 ${ }^{[6]}$. 目前, 对蓝藻打捞技术的研究主要 集中在工艺研制与应用方面. 如熊鸿斌等 ${ }^{[7]}$ 的 “浮式围栏引导-机械清除-投加剥离液辅助机械清除”, 中国 科学院南京地理与湖泊研究所研制的 “大型仿生式水面蓝藻清除设备” 及 702 所牵头研制的 “综合型”、“吸 取型” 和 “分离型”设备 ${ }^{[8]}$. 打捞对蓝藻生长及湖区水质的影响已受到关注, 周贝贝 ${ }^{\left[{ }^{[9]}\right.}$ 通过室内模拟打拹, 研 究了对数期与稳定期蓝藻打捞对蓝藻生长及氮、磷的影响, 表明不同生长阶段的人工打捞对铜绿微囊藻的 后续生长影响差异很大, 打捞可以有效控制内源氮、磷浓度; 徐宪根 ${ }^{[8]}$ 在巢湖东半湖水源区进行蓝藻打捞原 位控制实验, 重点研究夏季蓝藻打捞对蓝藻生长的影响及对营养盐的控制效应. 然而, 在蓝藻处于稳定生长 期的秋季, 湖岸带聚积蓝藻打捞对蓝藻生长及水质的影响目前鲜有报道.

巢湖是我国第 5 大淡水湖泊. 近年来,巢湖水体富营养化严重, 尤其在西北半湖蓝藻水华频繁暴发, 夏、 秋季大量藻体易向湖泊近岸迁移聚积 ${ }^{[10]}$. 因此, 在巢湖西北半湖近岸设置小型围隔, 通过原位打捞实验, 研 究秋季蓝藻打捞之后蓝藻生长及水质变化规律, 为浅水湖泊湖岸带蓝藻聚积防控提供科学依据.

\section{1 材料与方法}

\section{1 实验位置}

实验设置在富营养化水平较高、蓝藻频繁暴发的巢湖西北半湖近岸 (图 1a), 综合前期对该区域水下地 形的调查, 设置 3 个 $2 \mathrm{~m} \times 2 \mathrm{~m} \times 1 \mathrm{~m}$ 的小型防水围隔, 分别记为 $1^{\#} 、 2^{\#} 、 3^{\#}$ 围隔. 向湖中打人 8 根钢管, 围隔的四 角用绳牵引在钢管上加以固定. 此围隔用聚氯乙烯涂塑布经高温热合机接合而成, 㓞性及防水性能强, 为防止 风浪将湖水涌人围隔,围隔边缘用帆布包裹浮球(图 1b), 保证实验期间围隔水体与外界水体无交换作用.

\section{2 研究方法}

实验选择在秋季进行, 具体时间为 2014 年 9 月 24 日-10月 18 日,共 $24 \mathrm{~d}$. 实验开始前, 向每个围隔中 注人等体积的原位湖水, 用浮游生物网采集巢湖水华蓝藻, 并等质量加人到 3 个围隔中. 经藻细胞计数, 实 验期间围隔水体中 $95 \%$ (生物量) 以上蓝藻为微囊藻. 于 9 月 24 日 (第 $0 \mathrm{~d}$ ) 用单片鳃式过滤器 ( ZL 200910031268.0) 对 $1^{\#}$ 和 $2^{\#}$ 围隔进行蓝藻打捞清除. 单片鳃式过滤器由 400 目特制不锈钢筛网制成, 用水洜 将含藻水抽送至过滤器上端, 藻水自流而下, 清水透过篮网自流进人池中, 藻体截留在篮网表面顺势进人收 集槽, 每个围隔打捞时间约 2.5 h. $1^{\#} 、 2^{\#}$ 围隔中浮游植物密度由 $4.0 \times 10^{8}$ 和 $4.4 \times 10^{8} \mathrm{cells} / \mathrm{L}$ 分别下降至 $2.3 \times 10^{8}$ 和 $2.6 \times 10^{8} \mathrm{cells} / \mathrm{L}$, 平均下降 $41.7 \% .3^{\#}$ 围隔为对照组,未进行蓝藻打捞.

为监测打捞后蓝藻 $24 \mathrm{~h}$ 原位生长速率, 考察打捞对蓝藻短期恢复生长的影响, 于 9 月 25 日 14:00 至 9 月 26 日 $12: 00$ 每隔 $2 \mathrm{~h}$ 采样 1 次 (0:00-4:00 未进行采样),所采样品装人 $1 \mathrm{~L}$ 聚乙烯瓶中,现场用 $15 \mathrm{ml}$ 鲁哥试 剂固定. 为保证围隔水体体积不因采样过程而减小, 待 $24 \mathrm{~h}$ 采样结束后, 向围隔中加人纯水以补充采样消耗. 

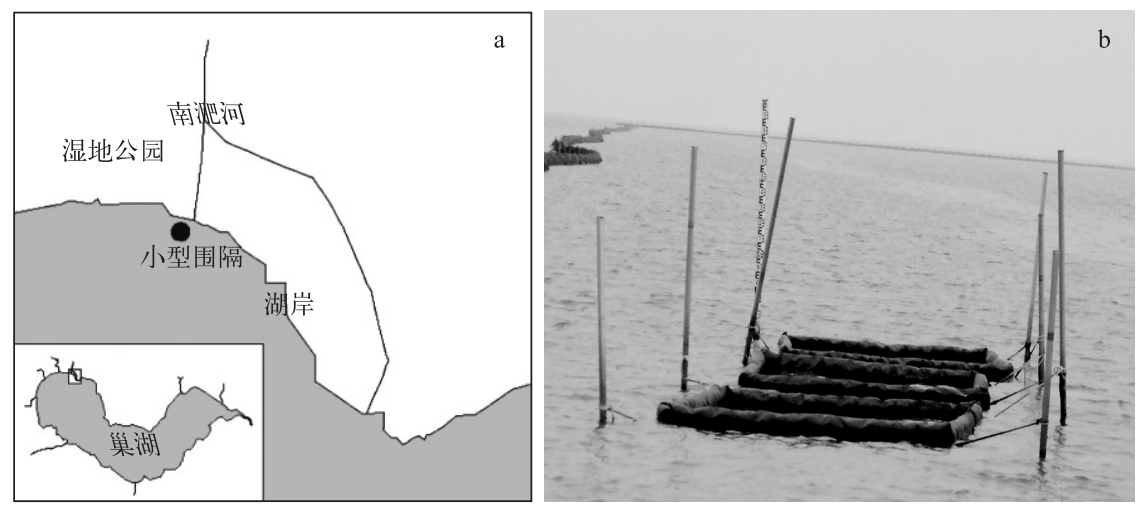

图 1 围隔位置及其布置方式

Fig. 1 The location and layout of the enclosures

按时间序列采样考察打捞之后蓝藻生长状况以及水体营养盐、有机物的变化规律. 未进行打捞之前记 为 $0 \mathrm{~d}$, 打捞后第 $2 \mathrm{~d}$ 记为 $1 \mathrm{~d}$, 以此类推, 分别在 $0 、 1 、 2 、 3 、 5 、 7 、 9 、 14 、 19 、 24 \mathrm{~d}$ 的 10:00 12:00 之间进行采 样, 遇特殊天气情况则调整采样时间. 用 $2.5 \mathrm{~L}$ 有机玻璃采水器采集围隔表层和底层混合水样,摚拌均匀,分 装人 2 个 $1 \mathrm{~L}$ 的聚乙烯瓶中, 置于冰盒并立即运回实验室处理分析. 剩余的水样倒回池中. 用等体积纯水补 充取水量,样品所测得浓度经校正后为实际浓度.

\section{3 分析方法}

1.3.1 气象数据及水体理化指标的测定 风速、风向采用便携式风速测定仪测定, 水体理化指标包括水温、 $\mathrm{pH}$ 值、溶解氧 (DO) 浓度、氧化还原电位 ( ORP) 、电导率、浊度由多参数水质分析仪 (U-50, 日本 Horiba) 测 定. 实验期间风向以偏东风为主, 风速介于 $1.0 \sim 3.4 \mathrm{~m} / \mathrm{s}$ 之间; 水温为 $21.6 \sim 25.6^{\circ} \mathrm{C}, \mathrm{pH}$ 值为 $8.1 \sim 9.0$, DO 浓度和 ORP 分别在 3. 66 9. $05 \mathrm{mg} / \mathrm{L}$ 和 97 227 mV 之间波动(图 2). 打捞对水体理化指标无显著影响 $(P>$ $0.05)$.

1.3.2 营养盐指标测定总氮 ( TN ) 、总磷 (TP) 浓度分别用碱性-过硫酸钾消解紫外分光光度法、过硫酸钾消 解-钿酸盐分光光度法测定 ${ }^{[11]}$, 溶解性总氮 (DTN)、溶解性总磷 (DTP) 浓度经过 $0.45 \mu \mathrm{m}$ 醋酸纤维滤膜过滤 后所得滤液按 TN、TP 测定方法测定, 颗粒态氮 $(\mathrm{PN})=\mathrm{TN}-\mathrm{DTN}$, 颗粒态磷 $(\mathrm{PP})=\mathrm{TP}-\mathrm{DTP}$; 溶解性无机氮 ( DIN, 包括 $\mathrm{NH}_{4}^{+}-\mathrm{N} 、 \mathrm{NO}_{3}^{-}-\mathrm{N} 、 \mathrm{NO}_{2}^{-}-\mathrm{N}$ ) 浓度经 $0.45 \mu \mathrm{m}$ 醋酸纤维滤膜过滤后用连续流动分析仪 (SKALAR, 荷 兰) 测定; 总有机氮 $(\mathrm{TON})=\mathrm{TN}-\mathrm{DIN}$.

1.3.3 蓝藻生长指标的测定 叶绿素 $\mathrm{a}(\mathrm{Chl} . \mathrm{a})$ 浓度经 $0.45 \mu \mathrm{m}$ 醋酸纤维滤膜过滤后用丙酮法进行提取测 定 $^{[11]}$. 细胞分裂频率测定及微囊藻原位生长速率 $(\mu)$ 的计算参照 $\mathrm{Tsujimura}^{[12]}$ 提出的细胞分裂频率法 (Frequency of dividing cells,FDC) 修正公式. 依此方法, 根据细胞形态可以将细胞分为单细胞、分裂期细胞和双细 胞, 双细胞是指细胞中央出现明显的隔痕. 每个样品至少计算 700 个细胞. 计算公式为:

$$
\begin{gathered}
\text { 细胞总数 }=S+D+2 P \\
f_{i}=D /(S+D+2 P) \times 100 \\
\mu=\frac{1}{n \cdot T_{\mathrm{d}}} \sum_{n}^{1} \ln \left(1+f_{i}-f_{\min }\right)
\end{gathered}
$$

式中, $S 、 D$ 和 $P$ 分别为单细胞、分裂期细胞和双细胞的数量; $T_{\mathrm{d}}$ 为细胞分裂所需要的时间, 其中微囊藻为 $3.3 \mathrm{~h} ; f_{i}$ 为采样时期的细胞分裂频率; $f_{\text {min }}$ 为连续测定过程中所得的最小细胞分裂频率; $n$ 为测定次数. 其中 $0: 00-4: 00$ 时段的 $f_{i}$ 值视为 0 .

1.3.4 有机物指标测定 高锰酸盐指数 $\left(\mathrm{COD}_{\mathrm{Mn}}\right)$ 参照《水和废水监测分析方法》测定 ${ }^{[11]}$. 水样经 $450^{\circ} \mathrm{C}$ 灼烧 后的 GF/F 膜过滤, 滤液用总有机碳测定仪 (TOC5000A, 岛津) 测定溶解性有机碳 (DOC). 用紫外可见分光 光度计 (UV2700, 岛津) 进行光谱扫描, 扫描波长范围为 $200 \sim 800 \mathrm{~nm}$. 用苂光分光光度计 (F-7000, 日立) 扫 
描三维苂光光谱 (EEMs), 扣除超纯水背景值, 并用 $0.01 \mathrm{mg} / \mathrm{L}$ 的硫酸奎宁校正, 所得光谱绘制成三维苂光 等高线图, 每个图中含有 20 条等高线. 实验所用的玻璃容器需要经 $10 \% \mathrm{HCl}$ 浸泡 $24 \mathrm{~h}$ 后再用超纯水冲洗干 净. 利用紫外-可见光谱及苂光光谱计算得到光谱参数,其定义及意义见表 1 .

表 1 苂光光谱参数、紫外-可见光谱参数描述 ${ }^{[13-15]}$

Tab.1 Description of fluorescence spectral parameter and ultraviolet-visible spectral parameter

\begin{tabular}{|c|c|c|}
\hline 参数 & 定义 & 意义 \\
\hline 腐殖质指数 $(H I X)$ & $\begin{array}{l}\text { 苂光光谱激发波长为 } 254 \mathrm{~nm} \text { 时, } H I X=\Sigma \\
(\mathrm{F} 435 \rightarrow \mathrm{F} 480) / \sum(\mathrm{F} 300 \rightarrow \mathrm{F} 345)\end{array}$ & $\begin{array}{l}H I X \text { 值较高 }(10 \sim 16) \text { 时, 表征溶解性有机物 } \\
\text { (DOM) 为陆源输人的腐殖质; 当 } H I X<4 \text { 时, } \\
\text { 有机物为内源贡献 }\end{array}$ \\
\hline 自生源指数 $(B I X)$ & $\begin{array}{l}310 \mathrm{~nm} \text { 激发波长下, 发射波长 } 380 \text { 与 } 430 \mathrm{~nm} \\
\text { 处若光强度的比值 }\end{array}$ & $\begin{array}{l}\text { 当 } B I X>1 \text { 时, 表明 } \mathrm{DOM} \text { 主要为内源且为新近 } \\
\text { 产生, } B I X \text { 在 } 0.6 \sim 0.7 \text { 之间, 表明自然水体 } \\
\mathrm{DOM} \text { 生产力较低 }\end{array}$ \\
\hline 若光指数 (FI) & $\begin{array}{l}\text { 激发波长在 } 370 \mathrm{~nm} \text { 下, 发射波长分别在 } \\
470 、 520 \mathrm{~nm} \text { 光谱强度的比值 }\end{array}$ & $\begin{array}{l}\text { 当 } F I<1.1 \text { 时, DOM 以陆源为主; 当 } F I>1.8 \\
\text { 时, DOM 以微生物活动及藻源为主 }\end{array}$ \\
\hline 光谱斜率比值 $\left(S_{\mathrm{R}}\right)$ & $\begin{array}{l}S_{\mathrm{R}}=S_{275-295} / S_{350-400} \text {; 光谱斜率 }(S) \text { 根据所在 } \\
\text { 波段的吸光度值非线性拟合所得 }\end{array}$ & $\begin{array}{l}S_{\mathrm{R}} \text { 与 DOM 相对分子质量呈反比, 与含量无 } \\
\text { 显著相关性 }\end{array}$ \\
\hline
\end{tabular}

\section{4 数据统计与分析}

用 Excel 2007、Origin 8.0 软件进行数据处理、图形绘制, 用 SPSS 18.0 软件进行数据统计分析.

\section{2 结果与讨论}

\section{1 打捞对蓝藻生长的影响}

2. 1.1 打捞对蓝藻短期生长的影响 打捞对蓝藻的生长速率会产生显著影响. 对照组、打捞组微囊藻的 $f$ 值 分别在 $2.5 \% \sim 5.5 \%$ 和 $3.2 \% \sim 7.1 \%$ 之间波动, 且均在 $14: 00$ 达到最大, 凌晨左右达到最小 (图 3a). 这是因 为凌晨光照条件较弱, 有效细胞分裂趋于停止; 白天光照条件较好, 有利于藻类的光合作用, 细胞分裂速度 也较快 ${ }^{[16]}$. 打捞组的 $f$ 值显著高于对照组 $(P<0.01)$, 这主要是由于打捞后蓝藻解除了 “密度制约”, 对照组 因未打捞, 微囊藻密度较高, 种群密度不能进行自我调节, 个体之间出现拥挤和竞争; 而打捞组中通过打捞 使得种群密度减小, 一定程度减轻了拥挤与竞争 ${ }^{[17]}$. 周贝贝等 ${ }^{[18]}$ 通过室内实验也证明打捞消除微囊藻生长 的密度制约. 对照组的 $f$ 值与理化因子 (外因) 之间均没有显著相关性, 而打捞组的 $f$ 值与温度、 $\mathrm{pH}$ 值和 ORP 存在显著相关性 (表 2), 表明处于聚积状态的微囊藻在打捞之后种群更易受到外因的影响, 而不是受内因 (种群密度) 的制约. 由公式 (3) 计算得到对照组和打捞组微囊藻原位生长速率分别为 0.18 和 $0.27 \mathrm{~d}^{-1}$. 此 结果与 Yamamoto 等 ${ }^{[19]}$ 在日本 Hirosawa-no-ike 水库 (与本实验所处纬度、水深接近) 秋季测得数据接近. 由 此表明打捞有利于促进藻细胞分裂, 增强藻细胞的生长活力, 从而可减缓藻源性有机物的释放. 本结果却与 徐宪根 $\left.{ }^{8}\right]$ 的研究结果相反, 可能是由于徐宪根研究的蓝藻不处于聚积状态, 不存在 “密度制约” 现象, 打捞反 而破坏蓝藻快速增殖的环境, 造成生长速率降低.

2.1 .2 打捞对蓝藻生长趋势的影响 打捞对蓝藻生长趋势的影响采用 $\mathrm{Chl}$. a 浓度表征. 在长时间水平上, 对 照组与打捞组均出现水体逐渐由蓝绿色向黄绿色转变, 并且实验前期表层漂浮蓝藻较多而后期相对较少. 这与周贝贝 ${ }^{[9]}$ 在圆桶模拟打捞、孙小静等 ${ }^{[20]}$ 在室内玻璃箱中所观察到的现象类似. 初始围隔水体 Chl. a 浓 度为 $309.5 \pm 3.7 \mu \mathrm{g} / \mathrm{L}$. 实验过程中, 对照组的 Chl. a 浓度变化范围为 $135.4 \sim 363.2 \mu \mathrm{g} / \mathrm{L}$, 打捞组 Chl. a 浓度 变化范围为 95.8 306.9 $\mu \mathrm{g} / \mathrm{L}$, 打捞组 Chl. a 浓度水平显著低于对照组 $(P<0.05)$, 说明在本实验周期内, 打 捞对蓝藻生物量的控制有显著效果. 对照组 Chl. a 浓度总体上呈现先波动上升再下降的趋势, 打捞组打捞 之后虽因解除“密度制约”, 出现生长小峰值, 但并没有遏制蓝藻秋季衰亡的趋势 (图 3b). 由实验期间 Chl. a 浓度趋于下降及蓝藻的颜色变化可定性表明, 蓝藻生长处于稳定期并趋于衰亡. 在秋季, 水温随着时间逐渐 下降 (图 2), 低于微囊藻生长最适宜温度范围 $\left(25 \sim 35^{\circ} \mathrm{C}\right)^{[21]}$, 且秋季湖区生态因子的改变, 围隔中可利用营 养盐的限制以及蓝藻生理特性的改变等均可能导致 Chl. a 浓度下降. 


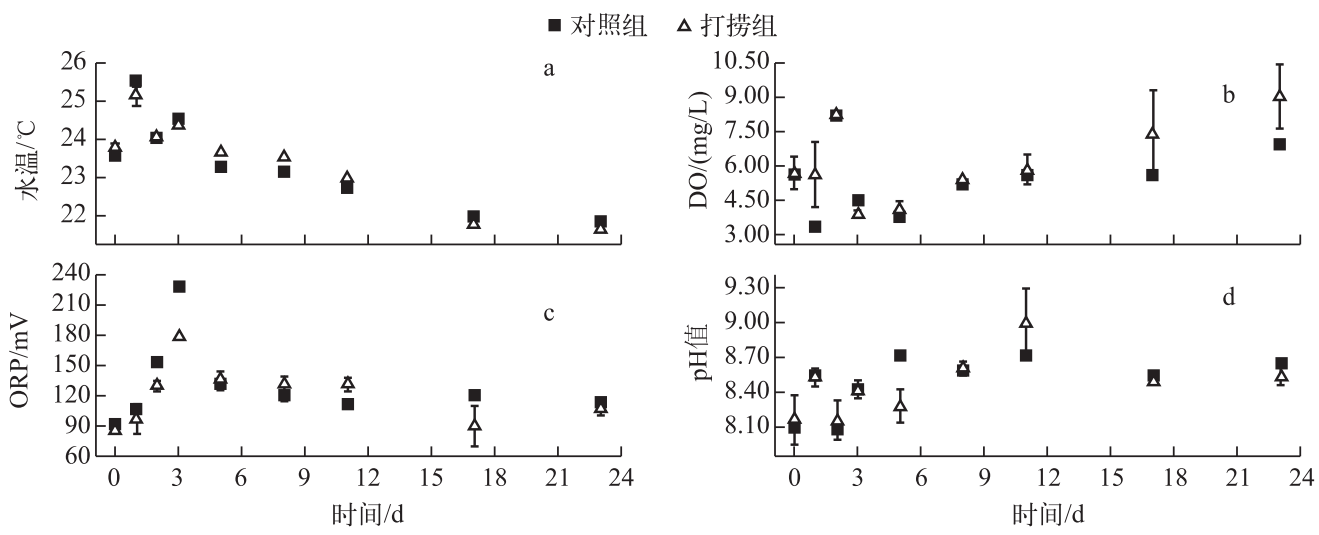

图 2 对照组与打捞组常规理化指标随时间的变化趋势

Fig.2 Variations of physico-chemical factors in the control and salvaging enclosures during the study periods

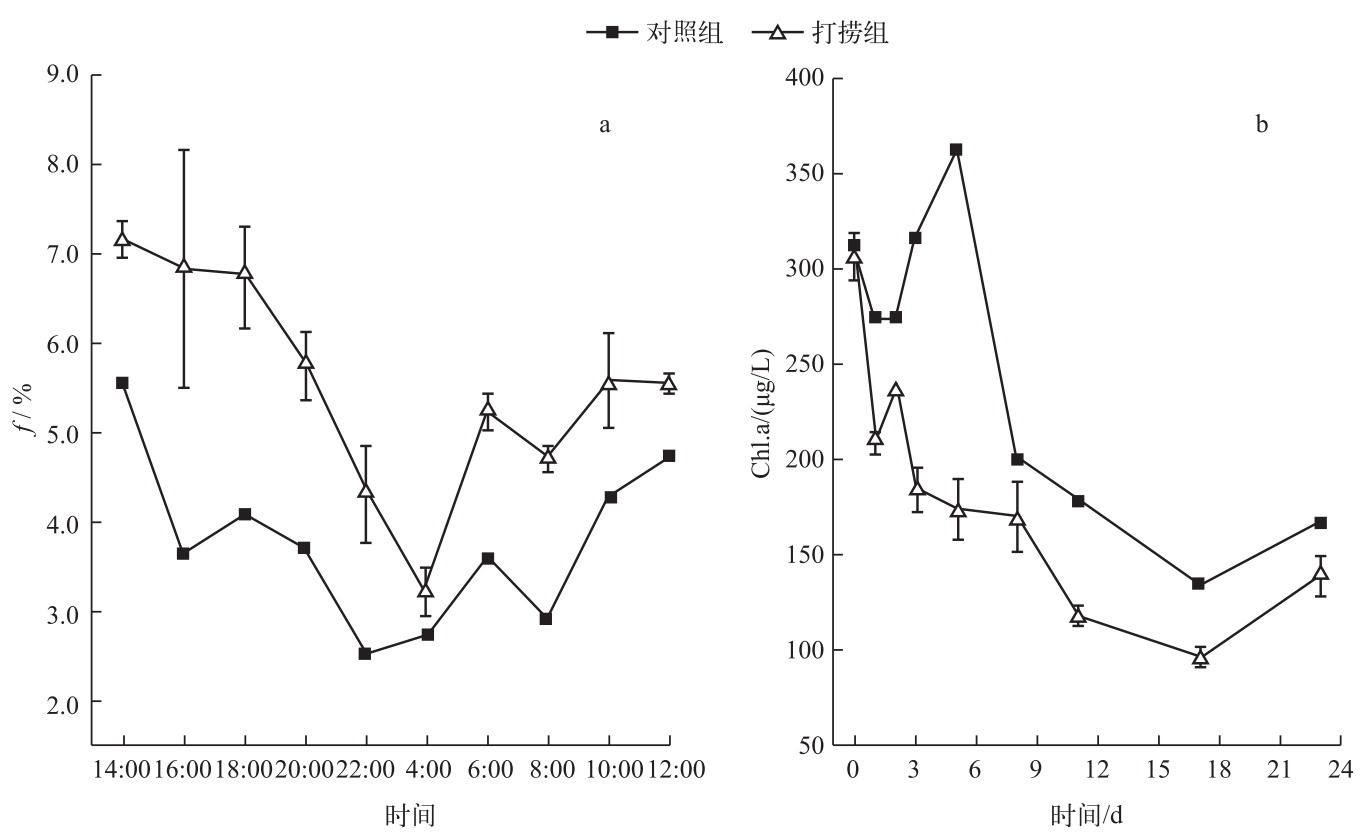

图 3 对照组与打捞组 $24 \mathrm{~h}$ 微囊藻细胞分裂频率 (a) 及 Chl. a 浓度 (b) 随时间的变化

Fig.3 Diel changes in $f$ values of Microcystis( a) and variations of chlorophyll-a concentration(b) in the control and salvaging enclosures

表 2 对照组与打捞组 $f$ 值与理化因子的相关性

Tab.2 Correlations between physico-chemical factors and $f$ values in the control and salvaging enclosures

\begin{tabular}{lllllll}
\hline & DO & T & pH 值 & ORP & 电导率 & 浊度 \\
\hline 对照组 $f$ 值 & 0.065 & 0.472 & 0.229 & -0.367 & -0.204 & -0.315 \\
打捞组 $f$ 值 & 0.527 & $0.849^{* *}$ & $0.675^{*}$ & $-0.643^{*}$ & -0.370 & -0.368 \\
\hline
\end{tabular}

**表示在 0.01 水平 (双侧) 上显著相关; *表示在 0.05 水平 (双侧) 上显著相关. 


\section{2 打捞对水体营养盐的控制效应}

打捞对 TN、PN、TON 浓度有极显著的控制效果 $(P<0.01)$ (图 4a). 对照组 PN 浓度占 TN 浓度的比例为 $66.4 \% \sim 90.2 \%$, 打捞组 PN 浓度占 TN 浓度的比例为 $37.7 \% \sim 82.2 \%$, 说明富藻水体中氮主要存在于藻体中, 利 用打捞技术清除蓝藻可有效控制水体中的氮负荷. 未打捞前, 围隔水体 TN 浓度为 $3.32 \pm 0.14 \mathrm{mg} / \mathrm{L}$, 通过打捞, 对打捞组中 TN 浓度的削减率为 $27.02 \%$. 打捞组的 3 种形态氮在打捞后 $2 \mathrm{~d}$ 内出现显著下降, 而后略有上升, $8 \mathrm{~d}$ 后迅速下降,并在 $17 \mathrm{~d}$ 达到最低值; 对照组前 $8 \mathrm{~d} 3$ 种形态氮浓度波动较小, 而后与打捞组的趋势相同; 第 $23 \mathrm{~d}$, 打捞组和对照组 3 种形态氮均出现大幅度上升. 稳定期的蓝藻开始趋于衰亡分解, 同时部分蓝藻会下沉 至湖底休眠. 实验初期漂浮藻体较多, 分解与沉降可以维持一段时间的动态平衡, 而随着分解过程中颗粒、胶 体之间的凝聚作用逐渐增强, 凝聚体的体积和质量不断增大, 使凝聚体更易趋向沉降 ${ }^{[20]}$, 使得水体中 TN、PN、 TON 浓度在 $8 \mathrm{~d}$ 之后开始显著下降. 第 $23 \mathrm{~d}$ 由于风浪较大, 使得下沉的颗粒发生再悬浮现象导致 3 种形态氮 突然升高,这与文献中报道的在浅水湖泊水体中 $\mathrm{TN} 、 \mathrm{TP}$ 浓度随风浪的变大而升高的结论一致 ${ }^{[22]}$.

打捞对 TP、PP 浓度具有较为显著的控制效果 $(P<0.05)$. 在打捞之后 $2 \mathrm{~d}$ 内, TP、PP 浓度均降至最小 值, 而对照组 TP、PP 浓度与初始值相比变化不大(图 4b). 对照组与打捞组中的 PP 浓度占 TP 浓度的比例 均在 $90 \%$ 以上, 表明富藻水体中的磷大量集中于藻体中, 清除藻体成为减少水体磷负荷的主要途径. 未打捞 前, 围隔水体 TP 浓度为 $0.30 \pm 0.04 \mathrm{mg} / \mathrm{L}$, 通过打捞, 对打捞组中 TP 浓度的削减率为 $26.4 \%$. 与氮形态变化 趋势不同, 对照组 TP、PP 浓度在 $3 \mathrm{~d}$ 之后就开始下降, 主要是因为蓝藻衰亡释放的磷浓度很低, DTP 浓度比 $\mathrm{TP}$ 浓度小 2 个数量级 (数据未展出), 分解所释放至水中的磷不足以抵消因沉降作用所携带的磷.
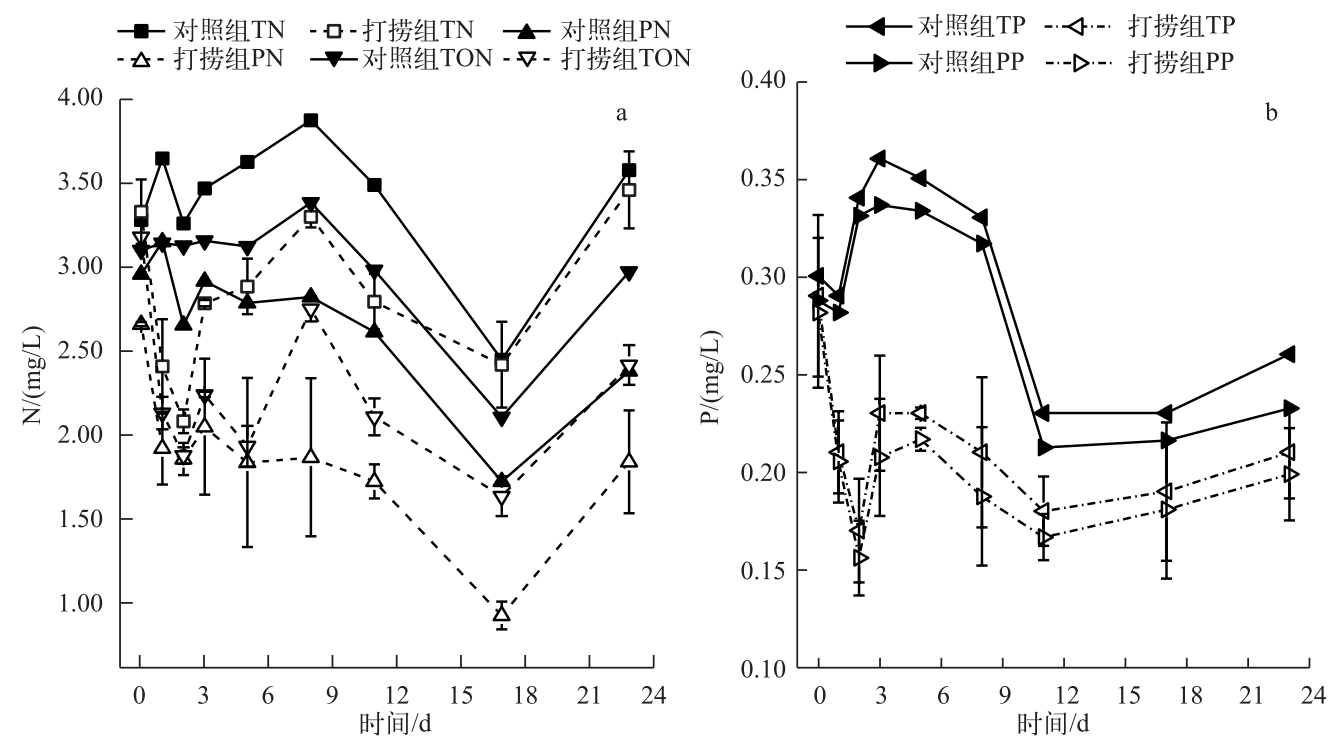

图 4 打捞对围隔水体氮( a)、磷 (b) 浓度的影响

Fig.4 Effects of salvaging on the concentrations of nitrogen (a) and phosphorus (b) in the enclosures

\section{3 打捞对水体有机物的控制效应}

打捞对水体有机物的控制表现为通过打捞减少藻源性有机物的释放. 苂光光谱特性是表征天然水体中 的有机质以及评估其来源的重要参数 ${ }^{[23]}$. 通过计算所得水样苂光参数值 (表 3) 结合其表征意义 (表 1) 可 知, 实验周期内水体 $H I X<4 、 B I X>1 、 F I>1.8$, 表明围隔水体的 DOM 主要为内源贡献. 本实验模拟蓝藻聚积, 外源有机物输人可忽略,蓝藻衰亡分解释放的藻源性有机物成为水体 DOM 变化的主要来源.

打捞对 $\mathrm{COD}_{\mathrm{Mn}}$ 具有极显著的控制效果 $(P<0.01)$. 巢湖多年的 $\mathrm{COD}_{\mathrm{Mn}}$ 平均浓度在 $5.6 \sim 7.0 \mathrm{mg} / \mathrm{L}$ 之 间 ${ }^{[24]}$, 而本实验模拟蓝藻聚积时, 水体 $\mathrm{COD}_{\mathrm{Mn}}$ 高于 $20 \mathrm{mg} / \mathrm{L}$, 说明局部蓝藻聚积导致的水体有机物污染十分 严重. 长期来看, $\mathrm{COD}_{\mathrm{Mn}}$ 呈现缓慢下降的趋势, 这主要是由于实验前期蓝藻漂浮在水体表层, 水中藻体对 
$\mathrm{COD}_{\mathrm{Mn}}$ 有很大贡献, 随藻体逐步沉降使 $\mathrm{COD}_{\mathrm{Mn}}$ 源减少, 但蓝藻衰亡分解过程中有藻源有机质释放, 两者综合 作用促使 $\mathrm{COD}_{\mathrm{Mn}}$ 缓慢下降. 打捞对控制 DOC 的效果不显著 $(P>0.05)$ (图 5a), 对照组与打捞组都出现 DOC 浓度缓慢增加并趋于平衡的趋势. 在蓝藻水华发生期间及发生后, 藻类代谢及衰亡分解的 DOC 成为水体 DOC 的主要来源, 易造成 DOC 积累 ${ }^{[25]}$, Minor 等 ${ }^{[26]}$ 还发现 DOC 浓度随着秋季 Chl.a 浓度下降而升高, 这与 本实验结论一致. 由于打捞组中藻体数量减少,后期 DOC 浓度得到一定控制.

研究表明 $S_{\mathrm{R}}$ 值与有机物的分子量呈反比 ${ }^{[27-28]}$, 因此打捞对水体有机质分子量的影响可通过 $S_{\mathrm{R}}$ 值的变 化表示 (图 5b). 打捞组与对照组的 $S_{\mathrm{R}}$ 值均呈现波动式起伏, 并趋于下降, 这与实验期间蓝藻分解释放的藻 源性有机物的降解有关 ${ }^{[15]}$. 打捞组 $S_{\mathrm{R}}$ 值显著高于对照组 $(P<0.05)$, 说明打捞使藻源性大分子有机物更易 降解为小分子有机物. Helms 等 ${ }^{[28]}$ 的研究表明, 光化学作用会导致 $S_{\mathrm{R}}$ 值增加, 微生物作用会减小 $S_{\mathrm{R}}$ 值. 本 实验为原位实验, DOM 的降解可能会受光化学与微生物共同作用. 对照组中蓝藻聚积可能会导致水体遮光 效应, 使得 DOM 的降解以微生物作用为主, 而打捞在一定程度上解除遮光效应, 增强 DOM 光化学作用, 导 致打捞组 $S_{\mathrm{R}}$ 值显著升高.

通过分析三维苂光光谱图中苂光峰值类型及强度, 可以得到水中荧光有机物的来源、组成及性质 ${ }^{[29]}$. 实验第 $0 、 8 、 23 \mathrm{~d}$ 的三维苂光图 (图 6) 表明, 实验水体有 4 类苂光峰: 类蛋白 $\mathrm{B}$ 峰 $\left(\lambda \mathrm{E}_{\mathrm{X}} / \lambda \mathrm{E}_{\mathrm{m}}=260 \sim 290 \mathrm{~nm} /\right.$ $300 \sim 310 \mathrm{~nm})$ 、类蛋白 $\mathrm{D}$ 峰 $\left(\lambda \mathrm{E}_{\mathrm{x}} / \lambda \mathrm{E}_{\mathrm{m}}=220 \sim 230 \mathrm{~nm} / 330 \sim 350 \mathrm{~nm}\right)$ 、紫外可见类富里酸 $\mathrm{A}$ 峰 $\left(\lambda \mathrm{E}_{\mathrm{x}} / \lambda \mathrm{E}_{\mathrm{m}}=\right.$ $230 \sim 250 \mathrm{~nm} / 400 \sim 450 \mathrm{~nm})$ 和可见类富里酸 $\mathrm{C}$ 峰 $\left(\lambda \mathrm{E}_{\mathrm{X}} / \lambda \mathrm{E}_{\mathrm{m}}=310 \sim 350 \mathrm{~nm} / 380 \sim 460 \mathrm{~nm}\right)$, 其中类蛋白 $\mathrm{D}$ 峰 为最强峰, 为生物降解来源的酪氨酸形成的苂光峰, 代表与微生物降解产生的芳香性蛋白类结构有关的苂 光基团 ${ }^{[27]}$, 此结果与宋晓娜等 ${ }^{[30]}$ 在太湖、刘菲菲 ${ }^{[31]}$ 在巢湖水华期间的研究结果一致. B、D 峰一般是藻源性 的苂光物质, $A 、 C$ 峰为外源性输入腐殖质与富里酸 ${ }^{[32]}$. 由于本实验模拟蓝藻聚积, 陆源有机质的输人可忽 略, A、C 峰的苂光强度均不大, 且变化不明显, 而蓝藻的藻源贡献使 $D$ 峰为最强峰. 未打捞之前, 对照组与打 捞组水体 D 峰的等高线均很密集, 但第 $8 \mathrm{~d}$ 对照组与打捞组的 D 峰出现显著差异, 打捞组 $\mathrm{D}$ 峰的等高线明 显比对照组 D 峰的等高线稀疏, 表明打捞对控制藻源性有机物的释放具有显著效果. 第 $23 \mathrm{~d}$, 对照组与打捞 组 D 峰的等高线疏密趋于接近, 并比第 $0 \mathrm{~d}$ 明显稀疏, 这可能与苂光物质的降解有关. 结合图 5a 与图 6 可 知, 本实验苂光强度的变化趋势与 DOC 浓度的变化趋势不一致. 有研究表明 ${ }^{[30]}$, DOM 的苂光强度与 DOC 浓度之间没有显著相关性, 不能用苂光强度表征 DOC 浓度. 这可能与 DOM 样品中含有一些不能发射苂光 的天然有机质以及与环境因素有关.
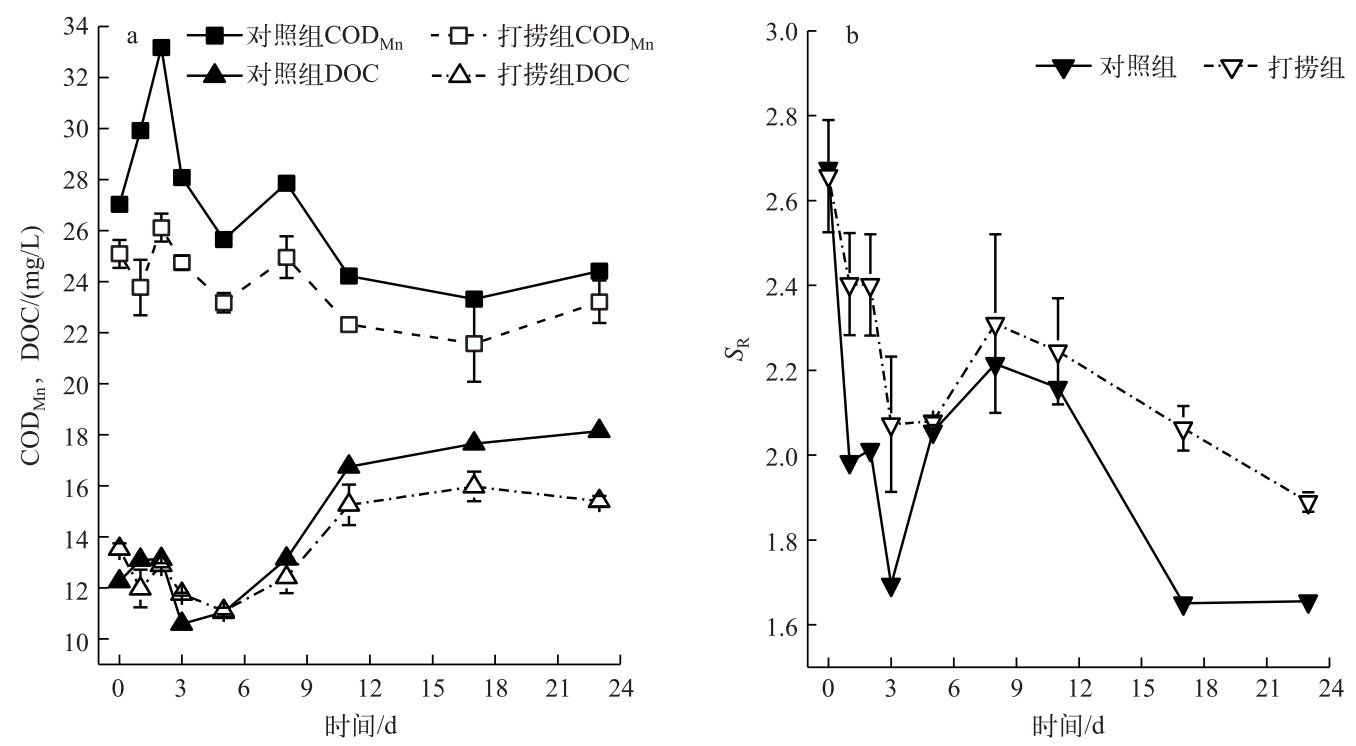

图 5 打捞对围隔水体 $\mathrm{COD}_{\mathrm{Mn}}$ 、DOC 浓度 (a) 和 $S_{\mathrm{R}}$ 值 (b) 的影响

Fig.5 Effects of salvaging on $\mathrm{COD}_{\mathrm{Mn}}$, DOC concentration(a) and $S_{\mathrm{R}}(\mathrm{b})$ in the enclosures 
表 3 实验期间不同处理围隔水体苂光参数的变化比较

Tab.3 Comparisons of fluorescence parameters in the control and salvaging enclosures during the study periods

\begin{tabular}{|c|c|c|c|c|c|c|}
\hline \multirow{2}{*}{ 时间 } & \multicolumn{2}{|c|}{$H I X$} & \multicolumn{2}{|c|}{$B I X$} & \multicolumn{2}{|c|}{$F I$} \\
\hline & 对照组 & 打捞组 & 对照组 & 打捞组 & 对照组 & 打捞组 \\
\hline $0 \mathrm{~d}$ & 2.42 & 2.30 & 1.13 & 1.12 & 2. 07 & 2. 06 \\
\hline $1 \mathrm{~d}$ & 2.29 & 1.99 & 1.13 & 1.15 & 2. 10 & 2. 03 \\
\hline $7 \mathrm{~d}$ & 2. 40 & 2.29 & 1.17 & 1.11 & 1.98 & 2. 04 \\
\hline $23 \mathrm{~d}$ & 2.55 & 2.53 & 1.04 & 1.04 & 1.97 & 1.95 \\
\hline
\end{tabular}
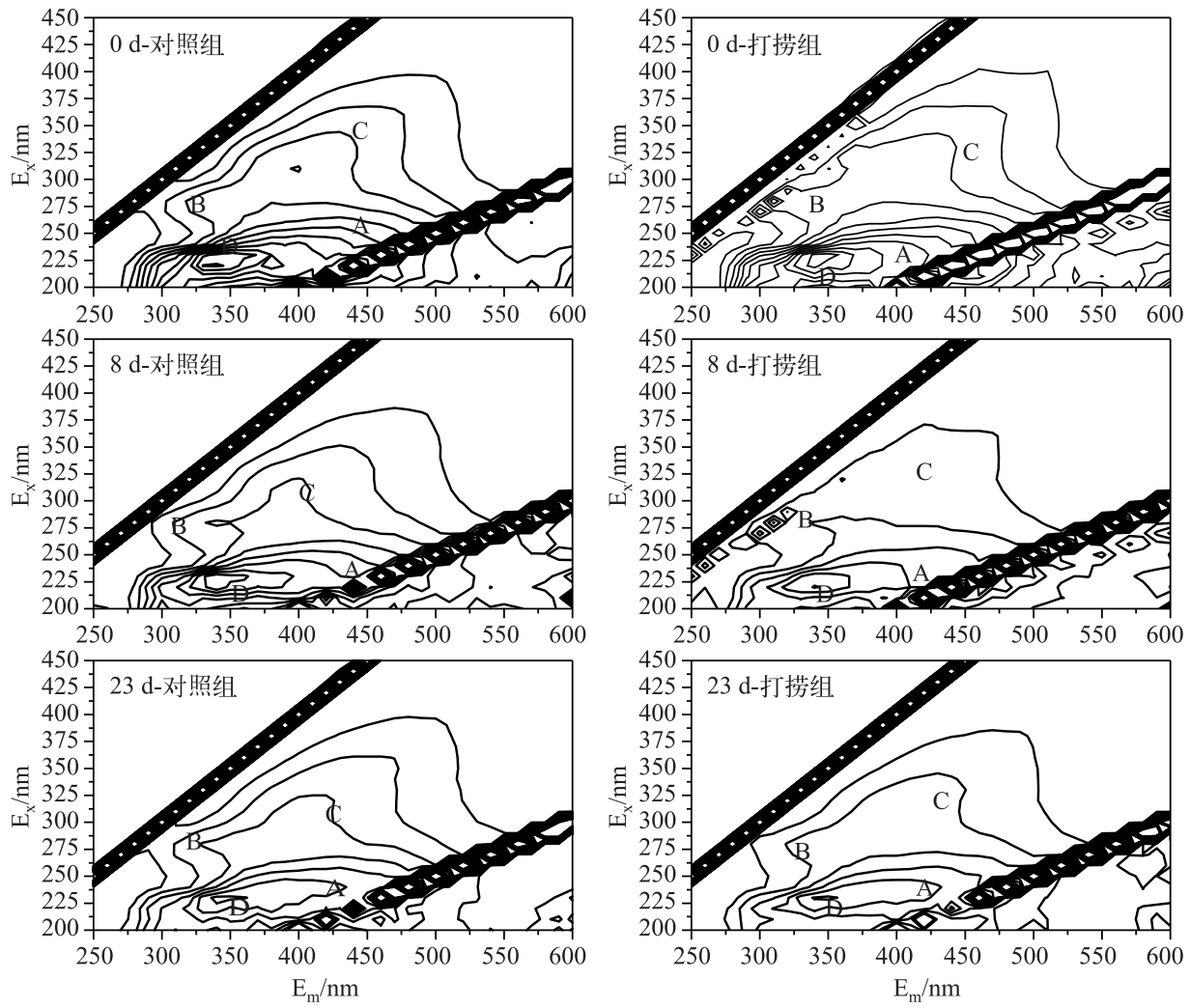

图 6 不同处理围隔水体 DOM 的三维苂光图谱

Fig.6 Fluorescence excitation-emission matrix of DOM in the control and salvaging enclosures

\section{3 结论}

1) 秋季聚积蓝藻打捞对水体初级生产力、蓝藻生物量有长效的控制作用,打捞后在短期内解除“密度制 约”, 增强藻细胞生长活力, 减少藻源污染物的释放, 且秋季打捞不会造成蓝藻水华二次暴发.

2) 蓝藻聚积水体中氮、磷主要集中在藻体内, 打捞成为减少富藻水体氮、磷负荷的主要途径.

3) 蓝藻聚积使水体有机物多为藻源性, 打捞对藻源性有机物的控制有显著效果; 且打捞使藻源性大分 子有机物更易降解为小分子有机物.

由此可知, 在大型浅水湖泊对秋季聚积蓝藻及时打捞, 能有效控制藻密度, 降低沉降的蓝藻种源, 减少 氮、磷、有机物负荷, 对蓝藻水华控制大有裨益.

致谢: 采样过程中得到曹晓祥、张开明等工作人员的协助, 数据处理绘图得到刘菲菲、何延召的指导, 在此表 
示诚挚的谢意!

\section{4 参考文献}

[ 1 ] 杨桂山, 马荣华, 张 路. 中国湖泊现状及面临的重大问题与保护策略. 湖泊科学, 2010, 22(6): 799-810. DOI $10.18307 / 2010.0601$.

[2 ] 李小平. 蓝藻运动与水华早期预防和控制. 自然杂志, 2008, 30(5) : 280-286.

[3] 李永慧, 李玉成, 王 宁等. 巢湖蓝藻死亡衰败过程中典型有害成分形成及控制对策. 湖泊科学, 2012, 24(4): 513-518. DOI 10.18307/2012.0402.

[ 4 ] 尚丽霞, 柯 凡, 李文朝等. 高密度蓝藻厌氧分解过程与污染物释放实验研究. 湖泊科学, 2013, 25(1): 47-54. DOI 10.18307/2013.0107.

[ 5 ] Tan X. Physiological and ecological characteristics in the life cycle of bloom-forming. Journal of Food, Agriculture \& Environment, 2012, 10(2) : 929-934.

[6] 邵路路, 陆开宏. 原位应急处理水源地蓝藻水华的物理技术研究及展望. 上海环境科学, 2013, 32(4): 160-165.

[ 7 ] 熊鸿斌, 李耀耀, 张 强. 巢湖蓝藻的机械清除工艺以及藻水分离实验研究. 环境工程学报, 2014, 8(2): 599-604.

[ 8 ] 徐宪根. 巢湖水源区蓝藻水华发生规律及控制响应 [学位论文]. 南京: 中国科学院南京地理与湖泊研究所, 2014.

[9] 周贝贝. 蓝藻打捞对水中氮磷及藻类生长的影响 [学位论文]. 南京: 南京师范大学, 2012.

[10] Chen YY, Liu QQ. On the horizontal distribution of algal-bloom in Chaohu Lake and its formation process. Acta Mechanica Sinica, 2014, 30(5) : 656-666.

[11] 国家环境保护总局《水和废水监测分析方法》编委会. 水和废水监测分析方法. 北京: 中国环境科学出版社, 2002:223-224, 243-250, 254-257, 670-671.

[12] Tsujimura S. Application of the frequency of dividing cells technique to estimate the in situ growth rate of Microcystis (Cyanobacteria). Freshwater Biology, 2003, 48(11):2009-2024.

[13] Chen ML, Price RM, Yamashita Y et al. Comparative study of dissolved organic matter from groundwater and surface water in the Florida coastal Everglades using multi-dimensional spectrofluorometry combined with multivariate statistics. Applied Geochemistry, 2010, 25(6): 872-880.

[14] Huguet A, Vacher L, Relexans S et al. Properties of fluorescent dissolved organic matter in the Gironde Estuary. Organic Geochemistry, 2009, 40(6) : 706-719.

[15] Zhang YL, Van Dijk MA, Liu ML et al. The contribution of phytoplankton degradation to chromophoric dissolved organic matter ( CDOM ) in eutrophic shallow lakes: field and experimental evidence. Water Research, 2009, 43 ( 18 ): 4685-4697.

[16] 吴晓东, 孔繁翔. 水华期间太湖梅梁湾微囊藻原位生长速率的测定. 中国环境科学,2008, 28(6): 552-555.

[17] Odum EP, Barrett GW. 陆健健等译. 生态学基础. 北京: 高等教育出版社, 2009: 229.

[18] 周贝贝, 王国祥, 杨 飞等. 人工打捞对铜绿微囊藻生长影响的模拟试验. 生态与农村环境学报, 2012, 28(3): 260-265.

[19] Yamamoto Y, Tsukada H. Measurement of in situ specific growth rates of Microcystis ( cyanobacteria) from the frequency of dividing cells. Journal of Phycology, 2009, 45(5) : 1003-1009.

[20] 孙小静, 秦伯强, 朱广伟. 蓝藻死亡分解过程中胶体态磷、氮、有机碳的释放. 中国环境科学, 2007, 27(3): 341-345.

[21］刘菲菲, 冯慕华, 尚丽霞等. 温度对铜绿微囊藻 (Microcystis aeruginosa) 和鱼腥藻 (Anabaena sp.) 生长及胞外有机 物产生的影响. 湖泊科学, 2014, 26(5): 780-788. DOI 10.18307/2014.0517.

[22] 孙小静, 秦伯强, 朱广伟等. 风浪对太湖水体中胶体态营养盐和浮游植物的影响. 环境科学, 2007, 28 (3): 506-511.

[23] 傅平青, 刘丛强, 吴丰昌. 溶解有机质的三维荧光光谱特征研究. 光谱学与光谱分析, 2005, 25(12) : 2024-2028.

[24] 吴 朝. 巢湖西半湖富营养化因子定量分析研究 [ 学位论文]. 合肥: 安徽农业大学, 2009.

[25] 叶琳琳, 史小丽, 张 民. 巢湖夏季水华期间水体中溶解性碳水化合物的研究. 中国环境科学, 2012, 32(2) : 318-323. 
[26] Minor EC, Simjouw JP, Mulholland MR. Seasonal variations in dissolved organic carbon concentrations and characteristics in a shallow coastal bay. Marine Chemistry, 2006, 101:166-179.

[27] 高 洁, 江 蹈, 李璐璐等. 三峡库区消落带土壤中溶解性有机质 (DOM) 吸收及苂光光谱特征. 环境科学, 2015, 36(1) : 151-162.

[28] Helms JR, Stubbins A, Ritchie JD et al. Absorption spectral slopes and slope ratios as indicators of molecular weight, source, and photobleaching of chromophoric dissolved organic matter. Limnology and Oceanography, 2008, 53 ( 3 ): 955-969.

[29] 陈小锋, 揣小明, 刘 涛等. 江苏省西部湖泊溶解性有机物光谱学特征和来源解析. 湖泊科学, 2012, 24(2): 259-266. DOI 10.18307/2012.0214.

[30] 宋晓娜, 于 涛, 张 远等. 利用三维荧光技术分析太湖水体溶解性有机质的分布特征及来源. 环境科学学报, 2010, 30(11): 2321-2331.

[31] 刘菲菲. 巢湖藻源性有机物释放特征及控制 [学位论文]. 南京: 中国科学院南京地理与湖泊研究所, 2014.

[32] Wu FC, Tanoue E. Isolation and partial characterization of dissolved copper-complexing ligands in streamwaters. Environmental Science \& Technology, 2001, 35(18) : 3646-3652. 